\title{
Effect of Calcium and Strontium on Mesoporous Titania Coatings for Implant Applications
}

\author{
Kathryn Grandfield ${ }^{1}$, Shiuli Pujari ${ }^{1}$, Marjam Ott ${ }^{1}$, Håkan Engqvist ${ }^{1,2}$, Wei Xia ${ }^{1,2}$ \\ ${ }_{1}^{1}$ Applied Materials Science, Department of Engineering Sciences, Ångström Laboratory, Uppsala University, Uppsala, Sweden; \\ ${ }^{2}$ BIOMATCELL, VINN Excellence Center of Biomaterials and Cell Therapy, Gothenburg, Sweden. \\ Email:wei.xia@angstrom.uu.se
}

Received January $11^{\text {th }}, 2013$; revised February $17^{\text {th }}, 2013$; accepted March $22^{\text {nd }}, 2013$

Copyright (C) 2013 Kathryn Grandfield et al. This is an open access article distributed under the Creative Commons Attribution License, which permits unrestricted use, distribution, and reproduction in any medium, provided the original work is properly cited.

\begin{abstract}
Increasing interest in the role of ions such as calcium and strontium in bone formation has called for the investigation of multifunctional ion-doped implant coatings. Mesoporous titania coatings incorporating calcium or strontium enabled a unique pore morphology and potential for drug delivery. Coatings were produced on titanium by an evaporation induced self-assembly method with the addition of calcium or strontium to the sol causing a shift in morphology from a hexagonally-packed to a worm-like porous network. Pore sizes ranged from $3.8-5 \mathrm{~nm}$ and coatings exhibited high surface areas between $181-215.5 \mathrm{~m}^{2} / \mathrm{g}$, as measured by $\mathrm{N}_{2}$ adsorption-desorption. Coatings were loaded with $1 \mathrm{mg} / \mathrm{ml}$ Cephalothin, and showed sustained release of the antibiotic over one week in vitro. Cell studies confirmed that the ion addition had no toxic effect on human-like osteoblastic SaOS-2 cells. The results of this study suggest the potential for mesoporous coatings with calcium or strontium incorporation for direct bone-interfacing and combined drug delivery implant applications.
\end{abstract}

Keywords: Mesoporous; Titania; Calcium; Strontium; Drug Delivery; Bone; EISA

\section{Introduction}

The chemistry, topography and morphology of implant surfaces are crucial determinants for implant success, rate of tissue regeneration and patient rehabilitation. For bone-interfacing applications, a highly tunable and functional biocompatible surface is desirable. Mesoporous coatings on implant materials, such as titanium, are ideal contenders due to the ability to tailor their pore size, chemical composition and topography in order to improve cell interaction, bone ingrowth and osseointegration, in general.

In addition, mesoporous materials have applications as potential drug delivery vehicles due to their high surface area and pore volume, suited for adsorption of small molecules and release via systemic or implantable local devices [1]. Several studies have demonstrated the uses of mesoporous materials such as silica, silicon, and bioactive glasses for drug delivery or bone growth induction [1-4].

The success of mesoporous materials in vivo is not only dependent on their pore structure, but also their chemistry. While silica is a commonly researched mesopor- ous carrier for drug delivery, in vitro testing in biologically relevant situations has shown it to degrade in a number of hours [5]. Therefore, titania, which is more resilient to in vivo degradation as demonstrated by Bass et al., may be a superior alternative for permanent implant applications, such as orthopaedic devices and dental implants [5]. Furthermore, mesoporous titania (MT) coatings have been shown to induce hydroxyapatite formation on their surface, an indicator of biocompatibility, and to exhibit an antibacterial effect against $E$. coli when loaded with antibiotics [6].

Human bone mineral is understood to consist of various ion-substituted apatites, thus the incorporation of select elements in biomedical materials is an accepted approach to improving biocompatibility and functionality $[7,8]$. Strontium is a well-known element used in the treatment of osteoporosis, in the form of orally administered strontium ranelate [9]. However, the release of $\mathrm{Sr}^{2+}$ ions locally into surrounding bone offers a similar therapeutic effect resulting in osteoclastic suppression and an increase in osteoblastic activity. Strontium incorporation into apatites and glass ceramics has been associated with increases in osteoblastic proliferation, osteogenic differ- 
entiation, collagen production and mineralization [10-12]. Likewise, calcium incorporated into the surface of Ti has shown increased alkaline phosphatase production, which is associated with osteoblastic differentiation, and acted as an active site to promote adhesion of proteins and cells to the implant surface [13]. Calcium ion implanted titanium was also found to accelerate the adsorption of phosphate ions on its surface, due to an increase in the positive active hydroxyls available, and thereby increase apatite formation [14].

Titania coatings can be produced by a number of methods [15]. The evaporation induced self-assembly (EISA) method used in this study is particularly useful due to the versatility it offers [6]. The coating morphology can be easy tuned by altering the many pre- and post-coating parameters including the chemical composition of the sol, dip-coating rate, and calcination time and temperature. In addition, pore shape and size can be tuned and tailored by the use of different structure-directing agents [2]. In this study, we investigate the effects of altering the chemical composition of the sol, by the addition of calcium and strontium ions, on coating morphology, drug delivery characteristics and cell interaction.

\section{Materials \& Methods}

\subsection{Coating Production}

Standard mesoporous titania (MT) and four mesoporous titania coatings with calcium or strontium (CMT1, CMT5, SMT01, SMT1) were produced using an evaporation induced self-assembly method (EISA) [6,16]. These four coatings were produced to consist of a final weight percentage of $1 \% \mathrm{Ca}, 5 \% \mathrm{Ca}, 0.1 \% \mathrm{Sr}$ and $1 \% \mathrm{Sr}$, respectively, with the maximum dopant concentrations determined by the saturation point of the ion salts in the sol.

Sol-gel solutions were prepared from mixing standard reagents according to Table 1. Columns A and B were mixed rigorously for 15 min separately and again after adding the contents of $\mathrm{B}$ to $\mathrm{A}$. This was followed by the addition of columns $\mathrm{C}$ and $\mathrm{D}$, with 5 and $30 \mathrm{~min}$ stirring after each respective addition. Titanium plates (Grade 2, $1 \mathrm{~cm} \times 1 \mathrm{~cm}$ ) were dip-coated with the sol-gel solution at a rate of $1 \mathrm{~mm} / \mathrm{min}$. The coated plates were aged at $-20^{\circ} \mathrm{C}$ for $24 \mathrm{hr}$, followed by calcination for $4 \mathrm{hr}$ at $300^{\circ} \mathrm{C}$ with a ramping rate of $1^{\circ} \mathrm{C} / \mathrm{min}$.

\subsection{Coating Characterization}

The coating crystallinity was analyzed using X-ray diffractometry (D5000, Siemens AG, Munich, Germany) with $\mathrm{Cu} \mathrm{K}_{\alpha}$ radiation $(\lambda=1.5418 \AA)$. The coating composition was determined using X-ray Photoelectron Spectroscopy (XPS/ESCA) (Quantum 2000, PHI, Minnesota, USA). Surface area was measured using N2 adsorptiondesorption (ASAP 2020, Micromeritics, USA) using Ar as the analysis gas at $77 \mathrm{~K}$. The morphology and porous structure were investigated using Scanning Electron Microscopy (SEM) (Leo 1550, Carl Zeiss AG, Oberkochen, Germany) with an acceleration voltage of $3 \mathrm{kV}$.

\subsection{Drug Loading and Release}

Plates were loaded with the antibiotic Cephalothin by soaking in a $1 \mathrm{mg} / \mathrm{ml}$ aqueous solution under vacuum for $2 \mathrm{~h}$, using $5 \mathrm{ml}$ drug solution per $1 \mathrm{~cm}^{2}$ coated plate. Drug-release was measured in a phosphate buffered saline solution (PBS) without $\mathrm{Ca}^{2+}$ or $\mathrm{Mg}^{2+}$ ions using a UV-Visible Spectrometer (UV-1800, Shimadzu Corp., Kyoto, Japan). The release data were fitted with the Higuchi model, which describes the drug release by diffusion based on Fick's law.

$$
\mathrm{Q}=\mathrm{k}_{\mathrm{H}} \mathrm{t}^{1 / 2}
$$

where $\mathrm{Q}$ is the amount of drug released at time $\mathrm{t}$ and $\mathrm{k}_{\mathrm{H}}$ is the Higuchi constant.

\subsection{Cell Culture and Viability}

Human osteoblast-like SaOS-2 cells were maintained in a DMEM/F12 culture medium supplemented with $10 \%$ fetal bovine serum (HyClone, Thermo Fischer Scientific Inc., Massachusetts, USA) and $2 \mathrm{mM}$ glutamine, 100 $\mathrm{U} / \mathrm{mL}$ penicillin, and $100 \mu \mathrm{g} / \mathrm{mL}$ streptomycin (SigmaAldrich, Germany). Cells were cultured in $75 \mathrm{~cm}^{2}$ flasks at $37^{\circ} \mathrm{C}$, in a humidified atmosphere with $5 \% \mathrm{CO}_{2}$. The growth medium was changed every 2 days, and detached using trypsin/EDTA when confluent. The SAOS-2 cell line, commonly used for composite toxicity and cyto-

Table 1. Constituents used to produce sol.

\begin{tabular}{cccccccc}
\hline & \multicolumn{3}{c}{$\mathrm{A}$} & \multicolumn{2}{c}{$\mathrm{C}$} & \multicolumn{2}{c}{$\mathrm{D}$} \\
\cline { 2 - 7 } & $\mathrm{P} 123(\mathrm{~g})$ & $\mathrm{EtOH}(\mathrm{g})$ & $\mathrm{Ti}(\mathrm{OEt})_{4}(\mathrm{~g})$ & $37 \% \mathrm{HCl}(\mathrm{g})$ & $\mathrm{H}_{2} \mathrm{O}(\mathrm{ml})$ & $\mathrm{Sr}\left(\mathrm{NO}_{3}\right)_{2}(\mathrm{~g})$ & $\mathrm{Ca}\left(\mathrm{NO}_{3}\right)_{2} 4 \mathrm{H}_{2} \mathrm{O}(\mathrm{g})$ \\
\hline SMT01 & 1 & 15 & 5.25 & 3.7 & 1 & 0.0031 & - \\
SMT1 & 1 & 15 & 5.25 & 3.7 & 1 & 0.031 & - \\
CMT1 & 1 & 15 & 5.25 & 3.7 & - & - & 0.061 \\
CMT5 & 1 & 15 & 5.25 & 3.7 & 0.5 & - & 0.328 \\
\hline
\end{tabular}


compatibility testing, retains many of the late stage markers of osteoblast differentiation.

Cell viability was investigated using the alamarBlue ${ }^{\circledR}$ (Invitrogen, Life Technologies Ltd., Paisley, UK) viability assay at 2, 7, and 14 days of culture. Tissue culture polystyrene (TCPS) and our standard MT were used as control surfaces. SaOS-2 cells were seeded on 6 different samples, $(\mathrm{n}=4)$, (TCPS, and $9 \mathrm{~mm}$ discs coated with MT, CMT1, CMT5, SMT01, and SMT1) in 48-well plates at a specific cell density of 7500 cells $/ \mathrm{cm}^{2}(19,000$ cells/mL). alamarBlue ${ }^{\circledR}$ is a non-toxic metabolic indicator for viable cells. Upon uptake into the cells, the dye reduced and fluoresced in proportion to the number of viable cells present on the sample. At each time point, the cell culture medium was removed and replaced with $0.500 \mathrm{ml}$ of alamarBlue ${ }^{\circledR}$ solution diluted 1:20 in phenol-free medium. The samples were further incubated for $3.5 \mathrm{~h}$ and aliquots of $150 \mu \mathrm{l}$ from each sample were read using the Multiscan MS spectrophotometer (Labsystem Multiskan MS, USA) at absorbance values between $\lambda_{\mathrm{ex}}=560 \mathrm{~nm}$ and $\lambda_{\mathrm{em}}=590 \mathrm{~nm}$.

\section{Results}

\subsection{Coating Characterization}

The ion-incorporated coatings analyzed by X-ray diffraction, shown in Figure 1, contained crystalline $\mathrm{TiO}_{2}$. The major peaks in the XRD pattern were consistent with the anatase phase of $\mathrm{TiO}_{2}$. Trace amounts of calcium and strontium were not detected and are believed to be below the detection limits of the instrument. However, XPS results confirm the molar ratio of strontium or calcium to titanium in the coatings. The values, measured by XPS, were in good agreement with the theoretical calculations, Figure 2.

BET measurements, shown in Table 2, indicated that pore size varied between 3.8 - $5 \mathrm{~nm}$ with corresponding

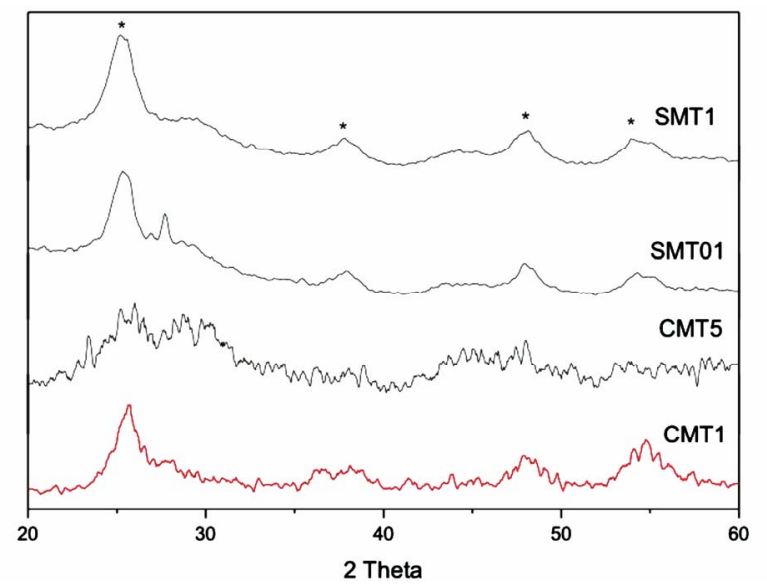

Figure 1. XRD spectra of the prepared coatings. Peaks marked with * indicate correspondence to anatase titania. pore volumes ranging from $0.17-0.28 \mathrm{~cm}^{3} / \mathrm{g}$. Nitrogen adsorption and desorption isotherms are shown in Figure 3.

SEM images revealed similar coating morphology for most substituted coatings. The surfaces are generally smooth and flat, with some cracks visible. A worm-like porous morphology is present in all coatings except the low concentration Sr-ion doped coating, Figures 4(a)(d). The worm-like morphology was much more discernable at higher magnifications, insets Figures 4(b) and (d). The original close packed hexagonal pore morphology of unaltered mesoporous titania is shown in Figure $\mathbf{5}$ for reference.

\subsection{Drug Release}

The release of the model antibiotic drug Cephalothin from ion-substituted coatings is reported in Figure 6. The coatings exhibited a slight initial burst release followed by sustained drug release over a two-week period. The drug release is reported in $\mu \mathrm{g} / \mathrm{cm}^{2}$ and therefore could be scaled with implant size or percentage of drugtreated surface. The drug release profile within 24 hours was agreement with the Higuchi model, Table 3, which indicates the antibiotic release is a diffusion-controlled process.

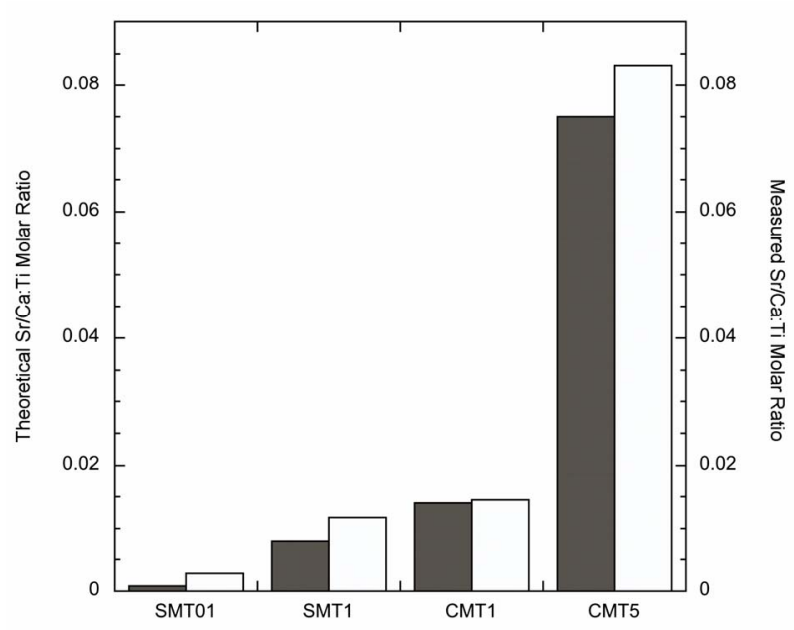

Figure 2. Graph of XPS results showing the agreement between theoretical (dark grey) and achieved (light grey) iondopant concentrations.

Table 2. $\mathrm{N}_{\mathbf{2}}$ adsorption-desorption measurements.

\begin{tabular}{lccc}
\hline & $\begin{array}{c}\text { BET Surface Area } \\
\left(\mathrm{m}^{2} / \mathrm{g}\right)\end{array}$ & $\begin{array}{c}\text { Pore Size } \\
(\mathrm{nm})\end{array}$ & $\begin{array}{c}\text { Pore Volume } \\
\left(\mathrm{cm}^{3} / \mathrm{g}\right)\end{array}$ \\
\hline SMT01 & 185.9 & 4.6 & 0.21 \\
SMT1 & 215.5 & 3.8 & 0.20 \\
CMT1 & 213.8 & 5.0 & 0.28 \\
CMT5 & 181.0 & 3.8 & 0.17 \\
\hline
\end{tabular}



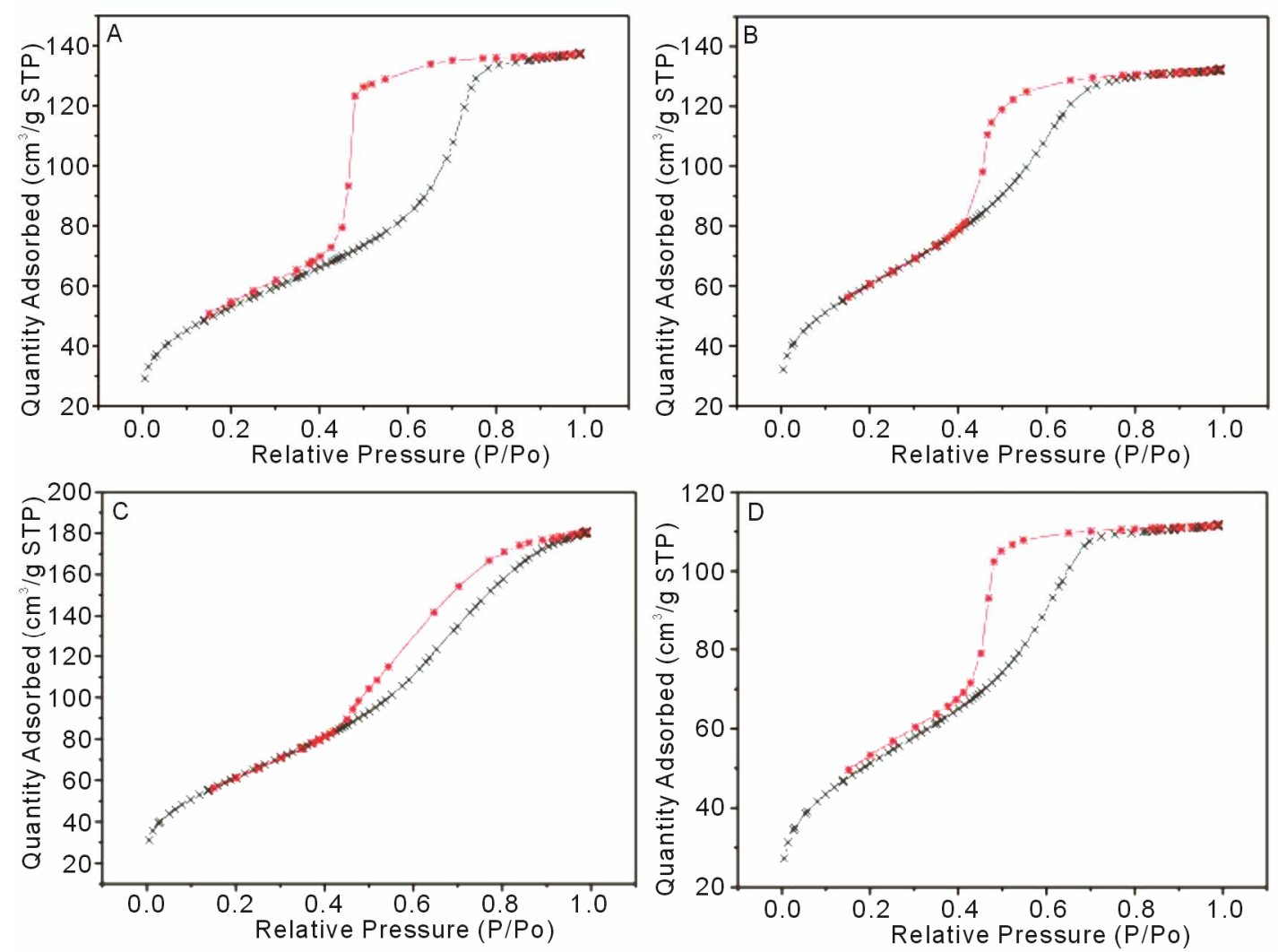

Figure 3. N2 adsorption-desorption isotherms from (A) SMT01, (B) SMT1, (C) CMT1 and (D) CMT5.
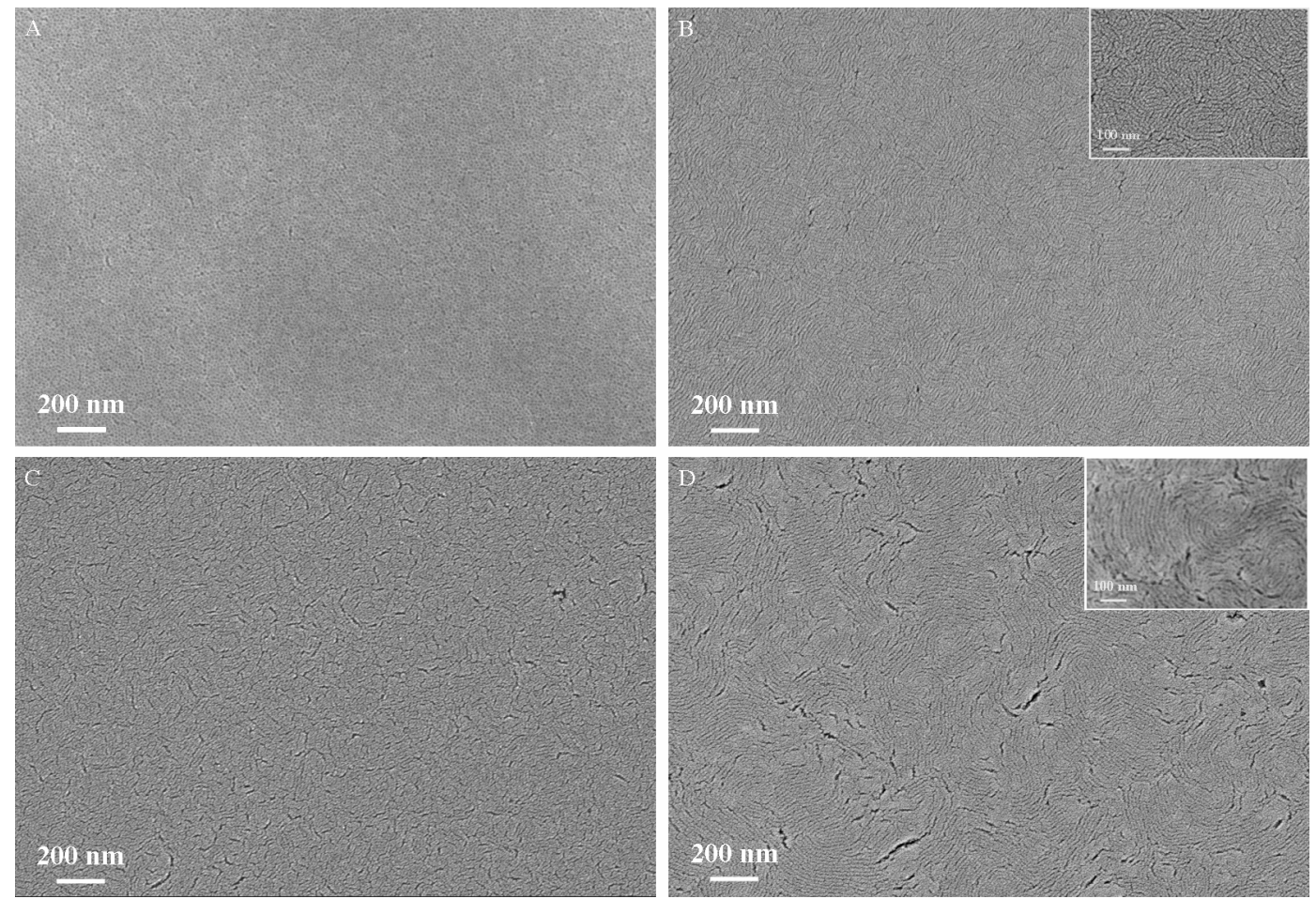

Figure 4. Low magnification SEM micrographs showing surface morphology of (A) SMT01, (B) SMT1, (C) CMT1 and (D) CMT5 with corresponding high magnification insets in (B) and (D). A worm-like pore morphology is present in all coatings except (A). 


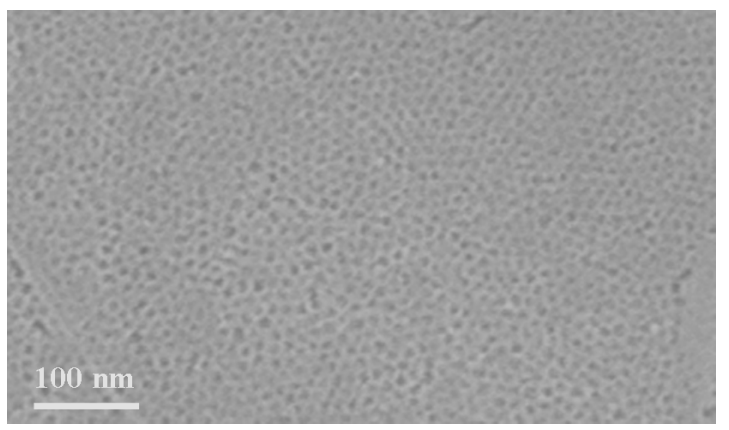

Figure 5. SEM micrograph of mesoporous titania without any ion additions. The morphology of the unaltered coating chemistry is a close packed hexagonal pore structure.

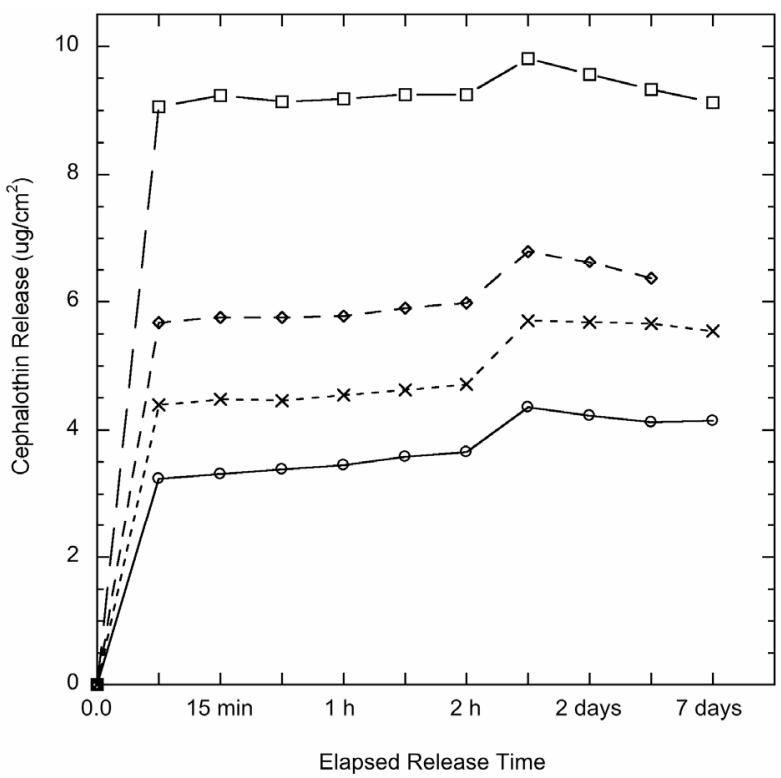

Figure 6. Cephalothin antibiotic release from coating surfaces o SMT01, $\square$ SMT1, $\diamond$ CMT1 and x CMT5 over one week in PBS as measured by UV-Visible Spectrometry.

Table 3. Higuchi constants calculated after $24 \mathrm{hr}$ drug release correlate well with diffusion-mediated release.

\begin{tabular}{lllll}
\hline & SMT01 & SMT1 & CMT1 & CMT5 \\
\hline $\mathrm{k}_{\mathrm{H}}$ & 0.236 & 0.153 & 0.244 & 0.288 \\
$\mathrm{R}^{2}$ & 0.99 & 0.98 & 0.996 & 0.998 \\
\hline
\end{tabular}

\subsection{Cell Viability}

The results of the alamarBlue ${ }^{\circledR}$ assay presented in Figure 7 indicated that the observed cell number was higher on the TCPS control substrates compared to the different titanium surfaces. However, there was no difference in terms of cell viability on cells grown on the standard MT surface and various calcium or strontium doped MT surfaces on titanium $(p>0.05)$. Cell proliferation gradually increased throughout the duration of the study.

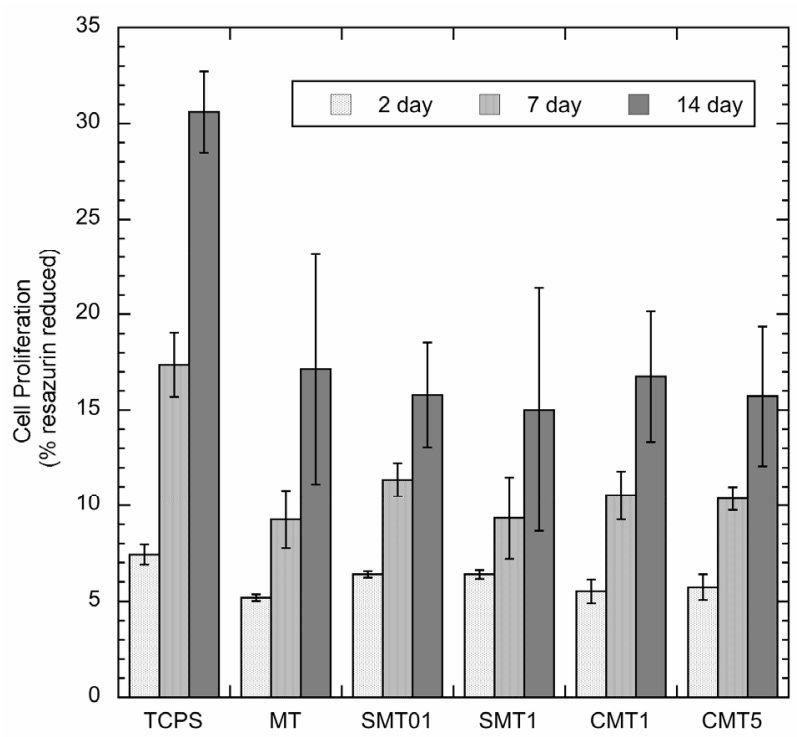

Figure 7. Proliferation of SaOS-2 cells on control and iondoped surfaces as determined by the alamarBlue ${ }^{\circledR}$ assay.

\section{Discussion}

Multi-functionality is an important feature of any modern implant coating. The ability to create a coating that can perform various functions simultaneously could improve the likelihood for, and reduce the time to, patient rehabilitation. Using coatings as a vehicle for site-specific drug delivery is one of the many properties a mesoporous coating can possess. The release of a model antibiotic drug, Cephalothin, was successfully demonstrated from the coating surfaces. Using the MT coatings as a drug delivery method could eliminate the need for, or reduce, systemic antibiotic usage. The release profile suggests a slight instantaneous burst release, which may be useful immediately after a surgery when the risk of infection and inflammation is the highest. Drug release via desorption of adsorbed molecules is the preferential method of release, since hydrolysis-induced erosion of carrier materials may lead to an undesirable fast and large burst release [17]. Nevertheless, in a study by Peterson et al. anticonvulsant drugs were successively incorporated into titania sols via hydroxyl groups and exhibited steady long-term release [18]. Yet, in our study, the release profile after the initial burst resembled a first-order release mechanism dependent on diffusion.

The addition of select elements, in this case calcium and strontium, to the titania coating has shown its most significant effect on the morphology of the implant surface. The surface morphology after incorporation of the elements of higher concentration takes on a worm-like structure, as opposed to the hexagonally packed system of pores observed in the non-ion doped mesoporous titania coatings of our previous work [6]. The destabilization 
of the close-packed structure, suggest that the calcium and strontium salts affect the normal self-assembly of the sol. Interestingly, the coating with the lowest addition of substitution element (SMT01) exhibited no change in morphology, suggesting that there exists a threshold ion addition that must be met to induce a morphological change, further work to confirm this is needed.

Specific tailoring of the surface area is an important factor to consider since the surface area determines the amount of drug-loading possible via adsorption [1]. The unique worm-like morphology created in this study by the addition of calcium and strontium could be employed for applications requiring a slower release mechanism, as in the study by Slowing et al. which demonstrated that mesoporous silica with a wormhole pore system released its load much slower than the same particles with parallel hexagonal pore channels [17].

BET surface area measurements indicated that the coatings with $1 \mathrm{wt} \%$ calcium or strontium have the largest pore surface area of $213.8 \mathrm{~m}^{2} / \mathrm{g}$ and $215.5 \mathrm{~m}^{2} / \mathrm{g}$, respectively. Interestingly, these two coatings also correspond to the coatings with the highest drug release determined from in vitro experiments, likely due to the direct correlation between surface area and the capacity for drug uptake. Mesoporous titania coatings studied previously showed a surface area of $172 \mathrm{~m}^{2} / \mathrm{g}$, lower than all the surface area measurements in this study from coatings which show a modified pore morphology [6]. The BET isotherms in Figure 3 exhibit Type IV curves, with hysteresis loops characteristic of pores with non-uniform size and shape.

The nanotopography of surfaces in contact with cells plays a significant role in cellular behavior. However, a consensus on the effect of nanotopography has yet to be reached in the field. In a study by Cai et al., it was found that titanium surfaces with differing nanotopographies, ranging from 2 to $21 \mathrm{~nm}$ pores, showed no significant difference in osteoblastic differentiation [19]. However, in the work by Bass et al. smaller pore sized (approximately $5 \mathrm{~nm}$ ) titania films produced by the EISA method promoted cellular adhesion, while the larger pore coating (approximately $10 \mathrm{~nm}$ ) were thought to pose a barrier to integrin assembly and cell spreading on the surface [20]. The pores produced in our work are on the range of $5 \mathrm{~nm}$.

The crystallinity of titania coatings has been shown to influence osseointegration. In a study on similar nanoporous titania films created by the EISA method, it was noted that the coating crystallinity increased with calcination temperature, resulting in a phase transition from amorphous to crystalline anatase [20]. XRD confirmed that the calcination process in our study produced anatase coatings, which are associated with improved osseointegration capabilities [21]. While XRD studies failed to show where the additional ions reside in the structure, it is expected that they form calcium and strontium titanates. Since the small addition of ions seems to be below the detection limit of the XRD, further investigation is needed to pinpoint the exact nature of the compound formed.

alamarBlue ${ }^{\circledR}$ is a metabolic indicator of viable cells and is initially introduced to the cells as the non-fluorescent dye, resazurin. Once reduced by metabolically active cells, resazurin fluoresces to its oxidized form, resorufin, allowing for the subsequent quantification of viable cells. In this work, the addition of calcium or strontium ions into mesoporous titania coatings showed no adverse effect on the proliferation of the SaOS-2 cells on the surface as determined from the alamarBlue ${ }^{\circledR}$ assay. However, the increase in cell proliferation throughout the study suggests that the titania surfaces were not cytotoxic.

\section{Conclusion}

Calcium and strontium ions have been incorporated into the sol for production of mesoporous titania coatings on titanium. The addition of calcium ions and high concentrations of strontium ions has resulted in a unique wormlike porous coating morphology with open pore network and increased surface area. The coatings provide an altered topography and pore surface area which may encourage osseointegration. The feasibility of using these coatings for local drug delivery has been demonstrated with the slow sustained release of Cephalothin over a one-week period. Cell studies confirmed that the ion addition had no toxic effect on human-like osteoblastic SaOS-2 cells. This study demonstrates the potential for using calcium and strontium to alter the morphology mesoporous titania coatings for bone-interfacing implant applications.

\section{Acknowledgements}

This work was supported by BIOMATCELL, VINN Excellence Center of Biomaterials and Cell Therapy, Gothenburg, Sweden and a VINNOVA VINNMER [grant 2010-01907] and a STINT Institutional Grant for Younger Researchers. Assistance with ICP measurements is gratefully acknowledged from SP Technical Research Institute of Sweden.

\section{REFERENCES}

[1] M. Vallet-Regì, F. Balas and D. Arcos, "Mesoporous Materials for Drug Delivery," Angewandte Chemie International Edition, Vol. 46, No. 40, 2007, pp. 7548-7558. doi:10.1002/anie.200604488

[2] X. Yan, C. Yu, X. Zhou, J. Tang and D. Zhao, "Highly Ordered Mesoporous Bioactive Glasses with Superior in Vitro Bone-Forming Bioactivities," Angewandte Chemie 
International Edition, Vol. 43, No. 44, 2004, pp. 59805984. doi:10.1002/anie.200460598

[3] W. Xia and J. Chang, "Well-Ordered Mesoporous Bioactive Glasses (MBG): A Promising Bioactive Drug Delivery System," Journal of Control Release, Vol. 110, No. 3, 2006, pp. 522-530. doi:10.1016/j.jconrel.2005.11.002

[4] H. A. Santos, J. Salonen, L. M. Bimbo, V. P. Lehto, L. Peltonen and J. Hirvonen, "Mesoporous Materials as Controlled Drug Delivery Formulations," Journal of Drug Delivery Science and Technology, Vol. 21, No. 2, 2011, pp. 139-155.

[5] J. D. Bass, D. Grosso, C. Boissiere, E. Belamie, T. Coradin and C. Sanchez, "Stability of Mesoporous Oxide and Mixed Metal Oxide Materials under Biologically Relevant Conditions," Chemistry of Materials, Vol. 19, No. 17, 2007, pp. 4349-4356.

[6] W. Xia, K. Grandfield, A. Hoess, A. Ballo, Y. Cai and H. Engqvist, "Mesoporous Titanium Dioxide Coating for Metallic Implants," Journal of Biomedical Materials Research Part B: Applied Biomaterials, Vol. 100, No. 1, 2012, pp. 82-93. doi:10.1002/jbm.b.31925

[7] R. LeGeros, "Apatites in Biological-Systems," Progress in Crystal Growth and Characterization of Materials, Vol. 4, 1981, pp. 1-45. doi:10.1016/0146-3535(81)90046-0

[8] F. Yao, J. P. LeGeros and R. Z. LeGeros, "Simultaneous Incorporation of Carbonate and Fluoride in Synthetic Apatites: Effect on Crystallographic and Physico-Chemical Properties," Acta Biomaterialia, Vol. 5, No. 6, 2009, pp. 2169-2177. doi:10.1016/j.actbio.2009.02.007

[9] P. Marie, "Strontium Ranelate: A Physiological Approach for Optimizing Bone Formation and Resorption," Bone, Vol. 38, No. 2, 2006, pp. 10-14.

doi:10.1016/j.bone.2005.07.029

[10] M. Looney, H. O. Shea and D. Boyd, "Preliminary Evaluation of Therapeutic Ion Release from Sr-Doped ZincSilicate Glass Ceramics," Journal of Biomaterials Applications, Vol. 27, No. 5, 2011, pp. 5111-524. doi:10.1177/0885328211413621

[11] E. Boanini, P. Torricelli, M. Fini and A. Bigi, "Osteopenic Bone Cell Response to Strontium-Substituted Hydroxyapatite," Journal of Materials Science: Materials in Medicine, Vol. 22, No. 9, 2011, pp. 2079-2088. doi:10.1007/s10856-011-4379-3

[12] G.-X. Ni, Z.-P. Yao, G.-T. Huang, W.-G. Liu and W. W. $\mathrm{Lu}$, "The Effect of Strontium Incorporation in Hydroxyapatite on Osteoblasts in Vitro," Journal of Materials Science: Materials in Medicine, Vol. 22, No. 4, 2011, pp. 961-967. doi:10.1007/s10856-011-4264-0
[13] B. Feng, J. Weng, B. Yang, S. Qu and X. Zhang, "Characterization of Titanium Surfaces with Calcium and Phosphate and Osteoblast Adhesion," Biomaterials, Vol. 25, No. 17, 2004, pp. 3421-3428. doi:10.1016/i.biomaterials.2003.10.044

[14] T. Hanawa, M. Kon, H. Doi, H. Ukai, K. Murakami, H. Hamanaka and K. Asaoka, "Amount of Hydroxyl Radical on Calcium-Ion-Implanted Titanium and Point of Zero Charge of Constituent Oxide of the Surface-Modified Layer," Journal of Materials Science: Materials in Medicine, Vol. 9, No. 2, 1998, pp. 89-92. doi:10.1023/A:1008847014938

[15] X. Liu, P. Chu and C. Ding, "Surface Modification of Titanium, Titanium Alloys, and Related Materials for Biomedical Applications," Materials Science and Engineering: $R$, Vol. 47, 2004, pp. 49-121. doi:10.1016/i.mser.2004.11.001

[16] C.-W. Wu, T. Ohsuna, M. Kuwabara and K. Kuroda, "Formation of Highly Ordered Mesoporous Titania Films Consisting of Crystalline Nanopillars with Inverse Mesospace by Structural Transformation," Journal of the American Chemical Society, Vol. 128, No. 14, 2006, pp. 45444545. doi:10.1021/ja060453p

[17] I. I. Slowing, B. G. Trewyn, S. Giri and V. S. Y. Lin, "Mesoporous Silica Nanoparticles for Drug Delivery and Biosensing Applications," Advanced Functional Materials, Vol. 17, No. 8, 2007, pp. 1225-1236. doi:10.1002/adfm.200601191

[18] A. Peterson, T. Lopez, E. Islas and R. Gonzalez, "Pore Structures in an Implantable Sol-Gel Titania Ceramic Device Used in Controlled Drug Release Applications: A Modeling Study," Applied Surface Science, Vol. 253, No. 13, 2007, pp. 5767-5771. doi:10.1016/j.apsusc.2006.12.094

[19] K. Cai, J. Bossert and K. D. Jandt, "Does the Nanometre Scale Topography of Titanium Influence Protein Adsorption and Cell Proliferation?" Colloids and Surfaces B: Biointerfaces, Vol. 49, No. 2, 2006, pp. 136-144. doi:10.1016/j.colsurfb.2006.02.016

[20] J. D. Bass, E. Belamie, D. Grosso, C. Boissiere, T. Coradin and C. Sanchez, "Nanostructuration of Titania Films Prepared by Self-Assembly to Affect Cell Adhesion," Journal of Biomedical Materials Research, Vol. 93, No. 1, 2010, pp. 96-106.

[21] R. Rohanizadeh, M. Al-Sadeq and R. Z. LeGeros, "Titanium Oxide Layers Obtained by Different Methods: Effect on Apatite Deposition," Key Engineering Materials, Vol. 240, 2003, pp. 449-452. 